\title{
TPE upgrade for enhancing operational safety and improving in-vessel tritium inventory assessment in fusion nuclear environment
}

\author{
M. Shimada ${ }^{\text {* }}$, C.N. Taylor ${ }^{\mathrm{a}}$, L. Moore-McAteer ${ }^{\mathrm{a}}$, R.J. Pawelko ${ }^{\mathrm{a}}$, R.D. Kolasinski ${ }^{\mathrm{b}}$, D.A. \\ Buchenauer $^{\mathrm{b}}$, and B.J. Merrill ${ }^{\mathrm{a}}$ \\ ${ }^{a}$ Fusion Safety Program, Idaho National Laboratory, Idaho Falls, ID 83415 U.S.A. \\ ${ }^{b}$ Sandia National Laboratories, Hydrogen and Materials Science Department, Livermore, CA 94550 USA
}

The Tritium Plasma Experiment (TPE) is a unique high-flux linear plasma device that can handle beryllium, tritium, and neutron-irradiated plasma facing materials, and is the only existing device dedicated to evaluate in-vessel tritium inventory in the nuclear environment for fusion safety. The electrical upgrade were recently carried out to enhance operational safety and to improve plasma performance. New DC power supplies and a new control center enable remote plasma operations from outside of the contamination area for tritium, minimizing the possible exposure risk with tritium and beryllium and eliminating heat stress issue. In November 2015, this TPE successfully achieved first deuterium plasma via remote operation after a significant three-year upgrade. Simple linear scaling estimate showed that the TPE is expected to achieve $\Gamma_{\mathrm{i}}{ }^{\max }$ of $>1.0 \times 10^{23} \mathrm{~m}^{-2} \mathrm{~s}^{-1}$ and $\mathrm{q}_{\text {heat }}$ of $>1 \mathrm{MWm}^{-2}$ with new power supplies. This upgrade not only improves operational safety of the worker, but also enhances plasma performance to better simulate extreme plasmamaterial conditions expected in ITER, FNSF, and DEMO for improving in-vessel tritium inventory assessment in fusion nuclear environment.

\section{Introduction}

The behavior of tritium in fusion reactor materials plays a major role in the material choice for blanket and divertor components because tritium retention and permeation determine in-vessel inventory levels and exvessel release quantities. These inventories are used in reactor safety assessments for licensing fusion facilities [1]. For example, the decision by the ITER organization to exclude carbon is based on predictions of unacceptable levels of tritium retained in co-deposited carbon layers. Deuterium-tritium (D-T) fusion reactions produce $14.1 \mathrm{MeV}$ neutrons that activate plasma facing components (PFCs) and cause defects in the structural materials of these components. In addition, possible combined effects, such as the irradiation response on tritium behavior (retention and permeation) in PFCs, have yet to be demonstrated. In a practical fusion environment, radiation damage by fusion neutrons, solid transmutations, and high radiation environment inside PFCs influence the behavior of hydrogen isotopes in PFCs, posing grand challenge in tritium in-vessel inventory assessment due to the unavailability of high flux $14 \mathrm{MeV}$ fusion neutron source. Knowing in-vessel inventories and ex-vessel releases will support licensing assessments, and help designers to deploy the PFCs materials needed in a burning plasma nuclear environment. ITER will demonstrate for the first time the controlled ignition and extended burn of D-T plasmas [2]. Safe operation of ITER dictates that invessel tritium concentrations retained within plasmafacing components must remain at acceptable levels. (At the present time, regulatory limits are $1000 \mathrm{~g}$ - $\mathrm{T}$ in vessel and $0.0001 \mathrm{~g} \mathrm{~T} / \mathrm{m}^{3}$ in the reactor cooling water [3]). Tungsten, a candidate PFC for the divertor in ITER, is expected to receive a neutron dose of $0.7 \mathrm{dpa}$ by the end of operation in ITER, and $>10 \mathrm{dpa}$ in FNSF and DEMO [3]. Challenges arise for both PFC and safety communities since most existing linear plasma devices lack the ability to handle radioactive materials, making it difficult to address this issue. As fusion materials research moves toward addressing the radiological/nuclear aspects of D-T operations in ITER and DEMO, the need for the development of the scientific understanding of tritium behavior in the PFCs under a burning plasma nuclear environment is critical.

Idaho National Laboratory (INL) operates a linear plasma device, known as the Tritium Plasma Experiment (TPE) [4]. The TPE is unique in that it combines four specialized elements: (a) the use of tritium, (b) a divertor-relevant high-flux plasma, (c) the ability to handle radioactive materials, as well as (d) beryllium [4]. TPE is located within the Safety and Tritium Applied Research (STAR) radiological facility, which is licensed for a total tritium inventory up to $16,000 \mathrm{Ci}\left(5.9 \times 10^{14}\right.$ $\mathrm{Bq})$. This is the threshold limit for a Hazard Category 3 Nuclear Facility [5], enabling us to handle moderate inventory of tritium and moderately activated/neutronirradiated materials. Despite its age, the TPE still stands as the only existing high-flux linear plasma device that can handle both tritium and neutron-irradiated material for in-vessel tritium inventory assessment in fusion nuclear environment [6], and plays an important role in improving in-vessel tritium inventory assessment in fusion nuclear environment.

In November 2015, this world's only tritium-capable linear plasma device successfully achieved first deuterium plasma via remote operation after a significant three-year upgrade. In this paper, we discuss the electrical upgrade, enhanced operational safety, simple linear scaling for expected ion flux density and heat flux,

author's email: Masashi.Shimada@inl.gov 
and ongoing collaborative research activity for in-vessel tritium inventory in neutron-irradiated tungsten.

\section{Tritium Plasma Experiment (TPE)}

\subsection{History of the TPE}

The TPE was originally established as the Tritium Plasma eXperiment (TPX) with RF plasma source in 1983 and operated from 1983 to 1992 in the Tritium Research Laboratory (TRL) at Sandia National Laboratories-Livermore. Decision was made to upgrade the TPX to hot cathode reflex arc with $\mathrm{LaB}_{6}$ source, rename to the TPE, and relocate to the Tritium System Test Assembly (TSTA) at Los Alamos National Laboratory due closure of the TRL in 1992 [7]. The TPE was returned to tritium operation in 1995 and operated from 1995 to 2002 in the TSTA. Decision was made to relocate the TPE to the STAR facility at INL due to closure of the TSTA in 2002, and built PermaCon enclosure around the TPE system (glovebox and power supplies) to minimize tritium release. The TPE was returned to deuterium operation in 2005 and tritium operation in 2009 in the STAR, INL. Decision was made in 2013 to setup new power supplies and control room outside of PermaCon enclosure (CA) to enable remote plasma operations from outside of the contamination area for tritium. From 2013 to 2015, the TPE has undergone major upgrades in its electrical and control systems: including replacement of aging power supplies, DC cables, feedthroughs, vacuum gauges, flow meters, cooling manifolds, cooling lines, instrumentation cables, and data acquisition systems.

\subsection{General description}

The TPE experimental system spreads in two areas: High-bay area (outside PermaCon enclosure) and inside PermaCon enclosure (contamination area/CA). Tritium containing equipment/materials are handled only inside PermaCon enclosure (CA). One water-cooled chiller, two air-cooled chillers, gas supply system, and two ion chambers are located in the north side (outside) of PermaCon enclosure. Three chillers are to provide isolated water-cooling system to remove heat from TPE system. Five disconnect switches, four standing power supplies, an instrument rack for a rack-mount power supply and a table are located in the south side (outside) of PermaCon enclosure. The main TPE components are located inside a stainless steel ventilated enclosure (VE), VE-TPE. The VE-TPE, an instrument rack and workbench are located inside PermaCon enclosure (CA). A stainless steel VE contains the TPE vacuum vessel (VV) consisting of a source flange, a target flange, tritium source system, heat tapes, four depleted uranium beds (Ubeds), two molecular sieve beds, two NI compactRIO DAQ chassis, valves, turbo molecular pump, dry scroll pump, thermocouples and ion chambers. The VE-TPE is posted as high contamination area (HCA), and the PermaCon enclosure is posted as contamination area (CA). Negative pressure is maintained by the STAR facility blower and the TPE blower located northeast corner of PermaCon enclosure to contain highly mobile tritium in the HCA and CA. The stainless steel $\mathrm{VV}$ and piping act as the primary containment, the VE acts as the secondary containment, and the PermaCon enclosure behaves as the third containment to prevent tritium release to High-bay area.

In the VE, Ultra-High Vacuum (UHV) components (Conflat flanges) and VCR fittings welded to stainless steel tubing are mainly used to minimize tritium release from the VV to the VE. Detail of the TPE experiment is given elsewhere [4,7]. For deuterium plasma operation, the exhaust gas will be directly released from the STAR tritium exhaust system to stack. For tritium operation, all the exhaust gas containing tritium will flow through depleted uranium beds (Ubeds) prior to release from the STAR tritium exhaust system to the stack. The tritium airborne concentrations inside PermaCon (room air for radiological protection purposes) and gas exhaust (process monitoring purposes) are continuously monitored by fixed flow- though ion-chambers.

\subsection{Description of major components}

The TPE is comprised of a plasma source holder, a target holder, pumping system and tritium capture system with Ubeds, which are described in detail below.

Source holder - it consists of water-cooled $\mathrm{Cu}$ plate, tungsten filaments, lanthanum hexaboride $\left(\mathrm{LaB}_{6}\right)$ cathode, molybdenum heat reflector, and tantalum holder [8]. The $\mathrm{LaB}_{6}$ cathode, which is a 6.35 -mm-thick 76.2 mm OD disk mechanically supported by a thin tantalum annulus attached to the molybdenum thermal reflector, is electrically common with the center post of the threeturn tungsten filament, the other end of which is electrically insulated from the remainder of the cathode structure and from the vacuum flange by a ceramic feedthrough. The vacuum flange and the entire vacuum chamber are electrically common with the anode of the plasma source, which is maintained at ground potential (PS\#1 positive in Figure 1). The electrical power supplies are then connected such that the cathode and filament center-post are at negative potential (PS\#1 negative and PS\#3 positive in Figure 1), while the outer connection to the filament is more negative to ensure electron repulsion (PS\#3 negative in Figure1).

Target holder - the vacuum flange and the entire vacuum chamber are electrically common with the anode of the plasma source, which is maintained at ground potential (PS\#2 positive in Figure 1). The sample is mounted by sandwiching tungsten mask, sample, heatsink discs and water-cooled $\mathrm{Cu}$ cooling plate with vented 1/4-20 bolts. The sample section is electrically isolated from the vacuum chamber with ceramic insulators. When biased, the sample is at negative potential (PS\#2 negative in Figure 1) with respect to the vacuum chamber, in order to accelerate the positively charged ions out of the plasma. For example, the plasma potential was typically between -5 and $0 \mathrm{~V}$, and an incident ion energy of approximately $100 \mathrm{eV}$ was achieved by biasing the target to $-100 \mathrm{~V}$ [4]. New retention and plasma-driven target holders were developed to achieve 
sample temperature up to $1000{ }^{\circ} \mathrm{C}$ and better control the sample temperature [9].

Magnets - a comparable axial magnetic field is established through the sample chamber, to direct the plasma from the source to the target, by 3 flat pancake magnets, which are powered in series by PS\#4. Pancake magnets are electrically isolated from rest of TPE system. In addition, a water-cooled solenoid magnet around the source guides the electrons during acceleration and directs the resulting plasma into the target chamber. The solenoid magnet is powered by PS\#5, generating an axial magnetic field of up to 0.03 Tesla. Solenoid magnet is also electrically isolated from rest of TPE system.

Depleted uranium beds (Ubeds) - the four uranium beds used for hydrogen-isotope storage as $\mathrm{UQ}_{3}$ (where $\mathrm{Q}$ $=\mathrm{H}, \mathrm{D}$, and/or T) were fabricated at Tritium Research Laboratory in Sandia National Laboratories in 1980s, each containing $1.27 \mathrm{~kg}$ of depleted uranium [7]. Within the primary container, the uranium powder is contained within three separate compartments connected in series, with 5-micron stainless-steel frits at each inlet and outlet to prevent migration of uranium powder. The ultimate storage capacity (stoichiometric $\mathrm{UQ}_{3}$ ) is 8.0 moles of $\mathrm{Q}_{2}$ gas (where $\mathrm{Q}=\mathrm{H}, \mathrm{D}$, and/or $\mathrm{T}$ ).

Diagnostics - a single Langmuir probe consisting of a $1 \mathrm{~mm}$ diameter tungsten wire surrounded by an alumina insulator is used to obtain the electron density, electron temperature, plasma space potential, and floating potential.in the TPE [4,7]. Detail of the single Langmuir probe is given elsewhere [4]. Czerny-turner spectrometer (Andor Technology, Shamrock SR-750-A) equipped with a back illuminated 2D (1024 x 255 pixels) CCD camera (Andor Technology, iDUS 420) was newly installed to distinguish $\mathrm{H}_{\alpha}(656.280 \mathrm{~nm}), \mathrm{D}_{\alpha}(656.104$ $\mathrm{nm}), \mathrm{T}_{\alpha}(656.045 \mathrm{~nm})$ in the plasma.

\section{TPE upgrade}

\subsection{Safety issue with previous TPE configuration}

Previously all the power supplies, instrumentation controls and data acquisition system were located inside the PermaCon enclosure (CA), creating the following operation safety issues:

- Increase of room temperature up to $35^{\circ} \mathrm{C}$ in the CA during 4-5 hours of tritium plasma operation.

- Increase of tritium and beryllium exposure risk

- No available space to put chair and desk in front of the previously control system.

- No capability of previous/old power supplies to remote control and setup safety features

Decision was made in 2013 to setup new power supplies and control room outside of PermaCon in order to eliminate the above four safety issues. Figure 1 shows the electrical power diagram for new power supplies, and Table 1 summarizes the power capability of newly installed TPE power supplies.
Table 1: Power capability of newly installed TPE power supplies and previous TPE power supplies (in parentheses).

\begin{tabular}{ccccc}
\hline ID & Use & $\begin{array}{c}\text { Voltage } \\
{[\text { VDC] }}\end{array}$ & $\begin{array}{c}\text { Current } \\
{[\text { ADC] }}\end{array}$ & $\begin{array}{c}\text { Power } \\
{[\mathrm{kW}]}\end{array}$ \\
\hline PS 1 & Discharge & $200(200)$ & $750(150)$ & $150(30)$ \\
PS 2 & Bias & $600(250)$ & $96(40)$ & $60(10)$ \\
PS 3 & Filament & $80(20)$ & $744(500)$ & $60(10)$ \\
PS 4 & Pancake & $50(40)$ & $600(500)$ & $30(20)$ \\
& magnets & & & \\
PS 5 & Solenoid & $32(7.5)$ & $450(200)$ & $15(1.5)$
\end{tabular}

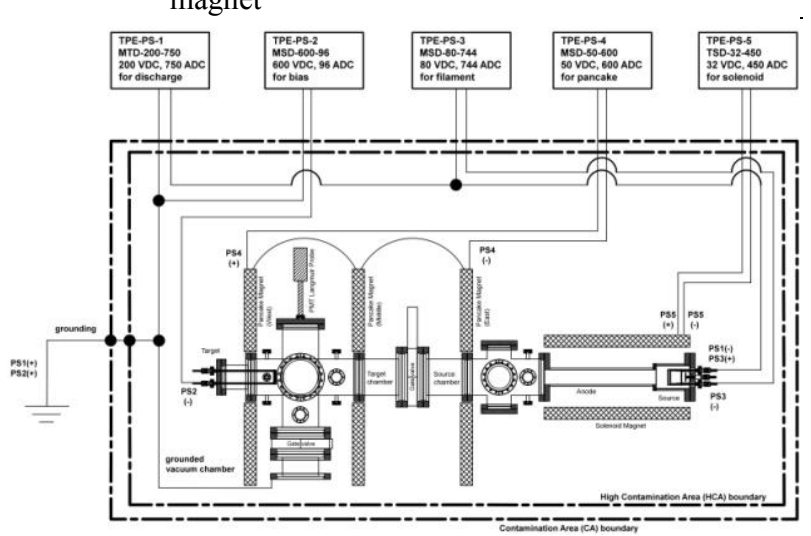

Figure 1: TPE power diagram for new power supplies.

\subsection{Risk of internal exposure to tritium}

With the previous configuration (before the TPE upgrade), operators need to work inside the PermaCon enclosure (CA) for approximately 8 hours per plasma discharge: 4 hours for plasma operation, 3 hours for bake-out operation, and 1 hour for sample changeout. Typically 100 plasma discharges were performed annually in the TPE, and operators also work inside the CA for additional 200 hour per year to perform open glovebox maintenance (OGM) for the source changout and other routine maintenance. Even though the airborne tritium concentration inside the CA is typically below $2 \mu \mathrm{Ci} / \mathrm{m}^{3} \sim 0.1$ DAC (derived air concentration), which is much lower than $1 \mathrm{DAC} \sim 20 \mu \mathrm{Ci} / \mathrm{m}^{3}$ for tritium, this 1000 work-hours per year in the $\mathrm{CA}$ can lead to significant risk of internal exposure to tritium. The tritium airborne concentrations inside PermaCon (room air for radiological protection purposes) and gas exhaust (process monitoring purposes) are continuously monitored by fixed flow-though ion-chambers (2 liter volume). Monthly bioassay program was used to monitor internal dose of operators to tritium.

\subsection{Upgrade in electrical system}

Five new power supplies (Magna Power, MTD, MSD, TSD series) were installed outside PermaCon (CA). Five (four standing and one rack-mount) power supplies utilize 480VAC (three phase), and isolation device were installed at the disconnect switches for maintenance activity downstream of power supply DC output. New DC cables (total length: $\sim 300 \mathrm{~m}$ ), studseals, crimp connectors, bus bars, and cable trays were installed both inside and outside the PermaCon enclosure (CA). All the electrical components (above 50 Volts) were reviewed and approved by INL's Authority 
Having Jurisdiction for National Electrical Code (NEC) to comply with the NEC code.

\subsection{Upgrade in instrumentation and control system}

One instrumentation and control (I\&C) rack outside the PermaCon enclosure (CA) houses a National Instruments (NI) compactRIO data acquisition (DAQ) chassis, a rack-mount power supply, a rack-mount PC, and two ion chamber controllers for tritium air monitor (one for TPE exhaust and the other for PermaCon room air). Another I\&C rack inside the PermaCon enclosure (CA) houses another NI compactRIO data acquisition (DAQ) chassis to monitor thermocouple readings and pressure gauge readings using NI Labview DAQ software, and to operate a Langmuir probe system. In addition, two uninterrupted power supplies (UPS) were installed to operate the NI DAQ system, Laboratory computers and monitors for 10 minutes in case of loss of facility power during plasma operation.

\subsection{Improvement in cooling system}

The following modification in the TPE cooling system were made to improve the heat removal capability: installation of new $50.8 \mathrm{~mm}$ ID manifold, installation of $\sim 15$ flow meters, $\sim 15$ in-line thermocouples, and increase of tube OD to $12.7 \mathrm{~mm}$ OD tubing. These modifications enable approximately a factor of 2 enhancements in the TPE cooling capability. Flow rate and inlet/outlet temperature are monitored in each critical cooling lines, and filtering system was installed for primary cooling loops. Additional two UPSs were installed to maintain the cooling water circulation for 10 minutes in case of loss of facility power during plasma operation.

\subsection{Decontamination of beryllium inside ventilated enclosure}

Tritium retention in beryllium was extensively studied during its tenure at the TSTA from 1995 to 2002 , heavily contaminating the TPE vacuum vessel and the ventilated enclosure (HCA) not only with tritium but also with beryllium. In 2014, beryllium was thoroughly decontaminated inside HCA to below $<<0.2 \mu \mathrm{g} / 100$ $\mathrm{cm}^{2}$, which is a DOE action level for beryllium contamination [10]. This decontamination allows workers to perform OGM without a full-face respirator.

\subsection{Reduction of internal exposure risk to tritium with remote control}

The new power supplies and NI compactRIO DAQ system enable workers to operate the TPE remotely from outside the PermaCon enclosure (CA). It includes remotely operating 2 turbo molecular pumps, a dry scroll pump, 3 water pumps, 9 bakeout heaters, 4 Ubed heaters, 20 pneumatic valves, 3 mass flow controllers, 15 flow meters, and a quadrupole mass spectrometer, and monitor 2 ion chambers, 68 thermocouple readings and 15 pressure gauge readings.

This remote operation minimizes operators to work inside the CA to only 1 hour per plasma discharge (for sample changeout purpose), reducing work hour to 100 work-hour per year in the CA with the 100 discharges per year. With the additional 200 hour/year for OGM, this remote operation can minimize worker internal exposure by reducing work hour up to 70 percent from 1000 work-hours per year with the previous configuration to 300 work-hours per year in the CA with the remote operation. This remote operation also enhanced operation safety by eliminating heat stress issue during plasma operation since now it is no longer required to stay in the $\mathrm{CA}$ during plasma discharge with remote operation.

\section{Simple estimate for expected ion flux density and heat flux after TPE upgrade}

In November 2015, the TPE successfully achieved first high-flux $\left(\sim 1.0 \times 10^{22} \mathrm{~m}^{-2} \mathrm{~s}^{-1}\right)$ long duration ( 2 hour) deuterium plasma via remote operation after a significant three-year upgrade, and the plasma characterization after the upgrade is being carried out with a Langmuir probe. Previous study of the systematic plasma characterization revealed that the ion flux density is power supply limited in the TPE with old power supplies [4], and the upgrade of the power supply system can bring the TPE even closer in line with the plasma condition of the ITER and DEMO PFCs.

Figure 2(a) shows the discharge current-voltage (IV) characteristic curve in reflex-arc sources. PISCES-A device operates with a reflex-arc source, and is capable of producing high-flux $\left(>10^{23} \mathrm{~m}^{-2} \mathrm{~s}^{-1}\right)$ with high discharge current: $I_{\text {dis }}[8]$. The previously obtained TPE discharge I-V characteristic curve were similar to that of PISCESA's low $\mathrm{I}_{\text {dis }}$ range, but higher $\mathrm{I}_{\mathrm{dis}}$ operation was not achieved due to the old power supply's maximum current: $\left(\mathrm{I}_{\mathrm{PS}}{ }^{\mathrm{max}}\right)^{\text {old }}$ of $150 \mathrm{~A}$ in the TPE. With the new power supply's maximum current: $\left(\mathrm{I}_{\mathrm{PS}}{ }^{\mathrm{max}}\right)^{\text {new }}$ of $750 \mathrm{~A}$, we plan to increase $\mathrm{I}_{\text {dis }}>200 \mathrm{~A}$, which is similar to PISCES-A near the future. The TPE can achieve the discharge power up to $\mathrm{P}_{\text {dis }}{ }^{\max }>20 \mathrm{~kW}$, as shown in Figure 2(a). Our previous study showed a linear dependence of discharge power on electron density $\left(n_{e}\right)$ and ion flux density $\left(\Gamma_{\mathrm{i}}\right)$, and the electron temperature $\left(\mathrm{T}_{\mathrm{e}}\right)$ of 5-10 eV does not change without installation of baffle tube [4]. The simple linear scaling estimates show that the TPE can achieve $\Gamma_{\mathrm{i}}{ }^{\max }$ of $>1.0 \times 10^{23} \mathrm{~m}^{-2} \mathrm{~s}^{-1}$ with new power supplies as shown in Figure 2(b). Heat flux density $\left(\mathrm{q}_{\text {heat }}\right.$ ) at negatively biased voltage can be simply expressed as $q_{\text {heat }} \approx-q_{i} \approx-e E_{i} \Gamma_{i}$. The old power supply's maximum bias voltage was $-200 \mathrm{~V}$, whereas the new power supply is capable of biasing up to $-600 \mathrm{~V}$. Maximum $q_{\text {heat }}$ with new power supply was estimated with $\Gamma_{\mathrm{i}}{ }^{\max }$ of $>1.0 \times 10^{23} \mathrm{~m}^{-2} \mathrm{~s}^{-1}$ in Figure 2(c). This simple estimate also shows that the TPE will be capable of reaching $\mathrm{q}_{\text {heat }}$ of $>1 \mathrm{MWm}^{-2}$ with new power supplies. Table 2 summarizes the expected ion flux density, heat flux with new power supplies. The ion flux density is expected to increase to $>1.0 \times 10^{23} \mathrm{~m}^{-2} \mathrm{~s}^{-1}$, and the heat flux is estimated to increase to $>1 \mathrm{MWm}^{-2}$ with new power supplies. It is important to note that these estimates were based on simple linear scaling that experimentally obtained previously at low discharge 
power $(<10 \mathrm{~kW})$ regime, and the new plasma parameter regime need to be experimentally confirmed at high discharge power $(>10 \mathrm{~kW})$ regime after the upgrade. This is, however, not a scope of this paper, and the experimental verification of this estimate will be topic of our subsequent publication.
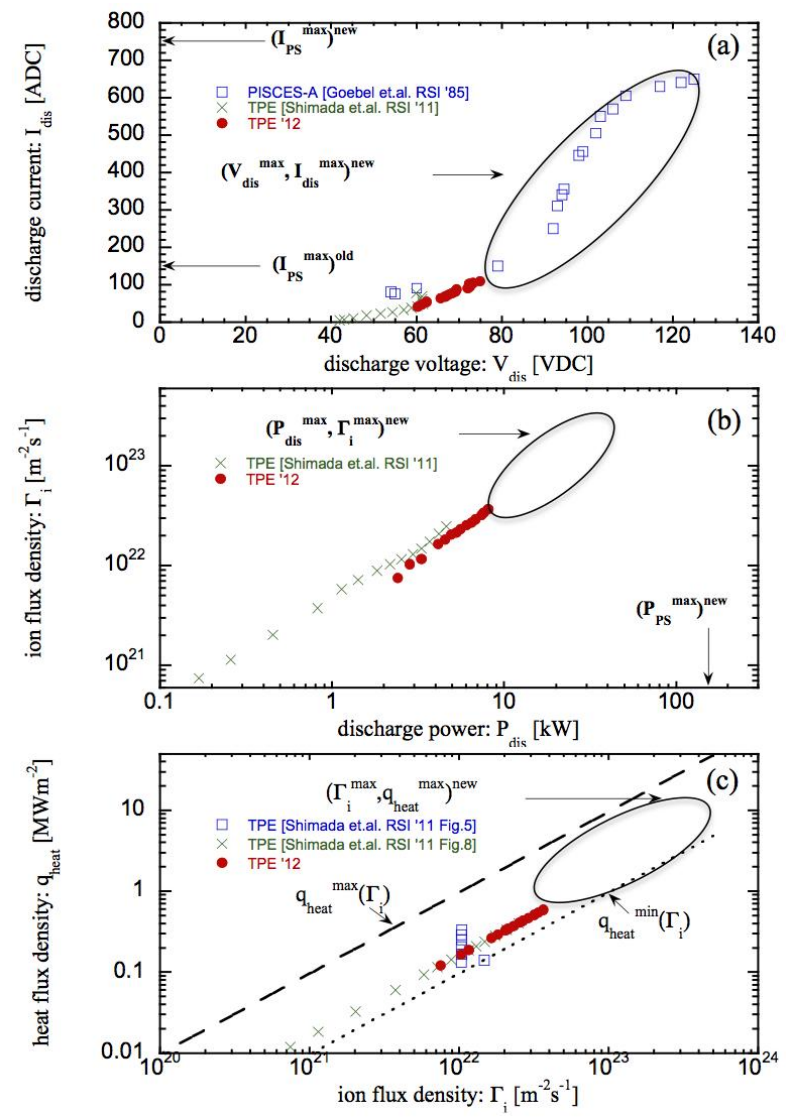

Figure 2: (a) I-V characteristic curve of TPE's old power supply and PISCES-A[7], (b) discharge power dependence on ion flux density, and (c) Ion flux density dependence on heat flux density

\section{Ongoing collaborative research activity for in- vessel tritium inventory in neutron-irradiated tungsten}

New US-Japan PHENIX collaboration (2013-2019) aims to investigate irradiation response of tungsten for DEMO and future fusion reactor, and plan to perform one-of-a-kind neutron-irradiation with $\mathrm{Gd}$ thermal neutron shield in the High Flux Isotope Reactor at Oak Ridge National Laboratory to simulate fusion neutron spectrum. The PHENIX Task 3 focuses on irradiation response of tritium behavior in neutron-irradiated tungsten and the TPE will help provide one-of-a-kind tritium retention database from neutron-irradiation tungsten.

\section{Conclusions}

The Tritium Plasma Experiment (TPE) is a unique high-flux linear plasma device that can handle tritium and neutron-irradiated plasma facing materials, and is the only existing device dedicated to evaluate in-vessel tritium inventory in the nuclear environment for fusion safety. The electrical upgrade were recently carried out to enhance operational safety and to improve plasma performance. Simple linear scaling estimate showed that the TPE will be capable of reaching $\Gamma_{\mathrm{i}}{ }^{\max }$ of $>1.0 \times 10^{23}$ $\mathrm{m}^{-2} \mathrm{~s}^{-1}$ and $\mathrm{q}_{\text {heat }}$ of $>1 \mathrm{MWm}^{-2}$ in new power supplies. This upgrade not only improves operational safety of the worker, but also enhances plasma performance to better simulate extreme plasma- material conditions expected in ITER, FNSF, and DEMO for improving in-vessel tritium inventory assessment in fusion nuclear environment. The TPE will help provide one-of-a-kind tritium retention database from neutron-irradiation tungsten with Gd thermal neutron shield under the USJapan PHENIX program (2013-2019).

Table 2: Summary of expected discharge performance, ion flux density, heat flux with new power supplies.

\begin{tabular}{ccc}
\hline Parameters & $\begin{array}{c}\text { TPE } \\
\text { (old PS) }\end{array}$ & $\begin{array}{c}\text { TPE upgrade } \\
\text { (new PS) }\end{array}$ \\
\hline $\mathrm{I}_{\text {dis }}^{\max }{ }^{\max }[\mathrm{ADC}]$ & 100 & $>200$ \\
$\mathrm{P}_{\text {dis }}{ }^{\max }[\mathrm{kW}]$ & 10 & $>20$ \\
$\mathrm{~V}_{\text {bias }}{ }^{\max }[\mathrm{VDC}]$ & -200 & -600 \\
$\Gamma_{\mathrm{i}}^{\max }\left[\mathrm{m}^{-2} \mathrm{~s}^{-1}\right]$ & $0.4 \times 10^{23}$ & $>1.0 \times 10^{23}$ \\
$\mathrm{q}_{\text {heat }}^{\max }\left[\mathrm{MWm}^{-2}\right]$ & 0.6 & $>1$ \\
\hline
\end{tabular}

\section{Acknowledgments}

This work was prepared for the U.S. Department of Energy, Office of Fusion Energy Sciences, under the DOE Idaho Field Office contract number DE-AC0705 ID14517.

\section{References}

[1] N. Taylor, C. Alejaldre, and P. Cortes, Fusion Sci. Technol. 64 (2013) 111

[2] ITER: www.iter.org

[3] ITER Preliminary Safety Report (RPrS), 3ZR2NC

[4] M. Shimada, R.D. Kolasinski, J.P. Sharpe, and R.A. Causey, Rev. Sci. Instru. 82 (2011) 083503

[5] "Hazard Categorization and Accident Analysis Techniques for Compliance with DOE Order 5480.23, Nuclear Safety Analysis Report", DOE-STD-1027-92 (1992)

[6] M. Shimada, G. Cao, T. Otsuka, M. Hara, M. Kobayashi, Y. Oya, and Y. Hatano, Nucl. Fusion 55 (2015) 013008

[7] R.A. Causey, D.A. Buchenauer, D. Taylor, W. Harbin, and B.A. Anderl, Fus. Technol. 28 (1995) 1144

[8] D.M. Goebel, Y. Hirooka, and T.A. Sketchy, Rev. Sci. Instru. 56 (1985) 091717

[9] D.A. Buchenauer, R.D. Kolasinski, M. Shimada, D. Donovan, and B.J. Merrill, Fus. Eng. Des. 89 (2014) 1014

[10] "Chromic Beryllium Disease Prevention Program" DOE, 10 CFR part 850 (1999) 